\title{
Analysis on the Impact of Private Credit on the Construction of Rural Households in Typical Highland Rural Areas
}

\author{
—Taking Gongbo'gyamda County as an Example \\ Song Lianjiu, Yuan Yuan \\ Plant Sciences College, Tibet Agriculture and Animal Husbandry University, Nyingchi Tibet, \\ 860000, China
}

Keywords: Private Finance; Farmers; Gongbo'gyamda County

\begin{abstract}
Based on the survey data of 159 households in Gongbo'gyamda County, Linzhi City, Tibet in 2017, this paper analyzes the impact of rural private credit on the reconstruction and expansion of rural households on the basis of research on rural private credit. The results show that due to the lack of social welfare and formal financial institutions, the reconstruction and expansion of rural households is inseparable from the subsidies of rural private credit; housing reconstruction and expansion will reduce the quality of life of farmers in the short term. Rural private credit still occupies a certain market share and affects the lives of Tibetan farmers in a unique way. Rural private finance is a product of social development. It plays an important role in the rapid development of rural economy and the increase of farmers' income.
\end{abstract}

Rural private credit is relative to standard finance. Generally speaking, rural private lending refers to the form and activities of providing financial credit or financing services for the production management and living consumption of farmers who cannot get funds from formal financial institutions by using non-standardized financial instruments through private ways without official supervision. The financial needs of $90 \%$ of farmers are met through rural private credit. In its unique way, rural private credit has made up for the shortcomings of formal financial institutions, met the financial needs of rural areas, promoted the economic development of rural areas, improved the utilization of resources, and stimulated the development of formal financial institutions, thus promoting the diversification of the rural financial system.

The lack of timely and convenient financial institutions has led to the emergence of rural private credit, and at the same time, it has also attracted academic attention to the use of rural private credit funds. Throughout domestic and international research, the main uses of rural private credit funds can be summarized into three parts: First, it is used to treat diseases for family members . Second, it is used for commercial operations and children's education, agricultural production and other activities with "productive" characteristics. Third, it is used for housing reconstruction and expansion and the preparation of children's marriage and other activities with the characteristics of 


\section{"living”.}

This paper attempts to explore the direction of Tibet's financial reform by analyzing rural private credit funds which are used for housing reconstruction and expansion. This paper also raise up some suggestions to regulate the order of rural private financial market in Tibet, improve the rural formal financial system, improve people's livelihood in Tibet's farming and pastoral areas, and speed up the construction of new countryside.

\section{Data sources}

In order to understand the impact of rural private finance on the reconstruction and expansion of rural households in gongbo'gyamda county more comprehensively and deeply, the author carried out a survey of "the research of the impact of rural private finance on the reconstruction and expansion of rural households" in gongbo'gyamda Town, the central town of gongbo'gyamda County, Zhongsa Township in the south, Bahe Town in the east, Zhula Township and Niangpu Township in the north, and Jiangda Township in the west in July 2017. Through questionnaires, interviews and other means, the household private finance of gongbo'gyamda County was surveyed. A total of 200 questionnaires were distributed and 186 questionnaires were collected. The recovery rate was 93\%, and 159 valid questionnaires were obtained. The questionnaire covers related information of farmers such as household characteristics, production and operation, and credit behavior related to housing reconstruction and expansion.

\section{Analysis of the Current Situation and Existing Problems of Private Lending}

\subsection{Analysis of Farmer's Credit Behavior}

The state offers certain subsidies, but most farmers still need to rely on rural private finance.Among the 159 sample farmer households, 140 households borrowed funds for their own housing reconstruction and expansion, accounting for $88.05 \%$ of the total sample farmer households; 108 households lent funds to other households for their housing reconstruction and expansion, accounting for $67.92 \%$ of the total sample farmer households.Through field visits, most farmers need 100 to 200 thousands to restore and expand their buildings. In the course of restoration and expansion of buildings, farmers can get 6,000 to 20,000 RMB for restoration and expansion subsidies of Tibetan affordable project. Farmers with good credibility can get 30 thousands loans from Agricultural Bank of China. However, there is still a large gap between capitals collected from financial subsidies and standard financial institutions and capitals needed for restoration and expansion of buildings.

The debt level has a positive correlation with the debt limit while the debt level has a negative correlation with the debt limit.Revealed by the investigated sources, the debt levels of farmers are divided into: less than 20,000 which accounts for 10.69\%; between 20,000 and 30,000 which accounts for $26.42 \%$; between 30,000 and 40,000 which accounts for $26.42 \%$ and more than 40,000 which accounts for $36.46 \%$. Therefore, more than half of the farmers have a debt level between 20,000 and 40,000 . The rural private credit is characterized by borrowing at the beginning of the year and repaying at the end of the year. Compared the debt levels with the level of creditors' rights, it can be found that the debt levels will increase along with the increase in the loan limits, whereas, the level of creditors' rights will decrease along with the increase of the loan limits. Reasons are as follows: the restoration and expansion for buildings need a large amount of capitals, but farmers can only get a small amount of money from affordable housing project subsidies and standard financial institutions are a small amount. Hence, the debt levels will increase along with the increase of the loan limits. However, farmers will borrow a small amount of money from many relatives and 
friends, resulting in a decrease in the creditors’ rights.

\subsection{Analysis of Credit Limits, Loan Period, Living Quality and Default}

Loan period will increase along with the increase of the time limit and the trend of the creditor rights present to be a" $\cap$ "shape. Compared the loan period of credit with the loan period of creditors rights, it can be found that the loan period of credit will increase along with the extension of the deadline, whereas, the loan period of creditors rights will present a" $\cap$ "shape along with the extension of the deadline. Compared the credit limit with the loan period of the credit, it can be found that in a debt relationship, both the credit limit and the loan period tend to increase and most of the loan periods are more than one year. Reasons are as follows: the restoration and expansion of buildings need a large amount of capitals and the agricultural production needs a long period, thus resulting in an unstable income of farmers. Therefore, farmers cannot repay the loans in a short term and they need a long period to repay all the debts. In a debt relationship, because the credit loans have a small amount of capitals, the loan period of creditors' rights is often within one year.

With the increase in credit limits, there is a growing rate of setting contract. Traditionally, both sides of the credit and debit are familiar with each other, so they only depend on personal credit rather than contracts. However, with the existence of "moral decline", dishonesty has been rampant and they even cannot trust their relatives and friends. Therefore, rural private credit does not need mortgage, but still needs to make a contract (commonly known as issuance of an IOU). Particularly, because the restoration and expansion of buildings need a large amount of capitals, contracts become a necessary procedure in the lending activities of restoration and expansion. In the credit relationship, there is a growing number of evidence of debt, with the increase in credit limit. In the contractual relationship, there are a larger number of verbal contracts, due to the small amount of credit limit.

Folk finance has a lower interest rate and rural private credit with usury feature has an extremely low percentage. The development of the market economy, farmers have growing market awareness. Financing merely affected by relationships is less and less, because it has a low interest rate. Standard banks of Tibet have an interest rate between $0.302 \%$ and $2.23 \%$.

\subsection{Short-term restoration and expansion of buildings will reduce farmers' living quality.}

For farmers, the restoration and expansion of buildings need a large amount of money. Although allowances from Tibetan Comfortable Housing Project can address partial lack of capitals, farmers still need to borrow loans from standard financial institutions and the rural private credit to make up for the rest capitals. The income is not stable, because local farmers have a strong agricultural characteristic which is vulnerable to the defect in agriculture. Double pressure from loan due period and interest rate forces farmers to work outside and save current expenses to pay off the debt, which undoubtedly reduces their living standards. According to the investigation, 28.93\% investigated farmers believe that their living standards have been reduced after the restoration and expansion of buildings. But farmers are satisfied to their new homes. In accordance with the survey, 62.89\% investigated farmers are satisfied to their new homes. Most farmers say that it is the first that they live in a bright and spacious house with a separate bedroom and kitchen and complete supporting facilities, such as water, electricity, gas and communications. After building new houses, farmers' living sites are separate from those of animals and the living environment and sanitation conditions have been improved. 


\subsection{Most farmers accept standard financial institutions, but they still leave a lot to achieve.}

Standard financial institutions in Tibet are granted vigorous support and special preferential policies. Hence, it is commonplace for farmers to borrow petty loans in Tibet, which has a close relationship with the successful implementation of benefit farming policy in Agricultural Bank of China, such as "gold card", "silver card", and "copper card". According to credit records and incomes, farmers are divided into "excellent”, "preferable”, "general” and "poor". All classes, except for "poor", are granted "gold card", "silver card", and "copper card" respectively and corresponding amount of loans. When farmers restore and expand their buildings, 88.68\% petty loans are obtained through gold card, silver card and copper card. Farmers are $72.33 \%$ satisfies to petty loans of banks.

Farmers would like to select standard financial institutions for loans over rural private credit. $66.67 \%$ farmers say that the interest of bank loans is lower than that of rural private credit. Only 8.18\% farmers investigated think the rural private credit is better, because it is more convenient and there are few procedures. In addition, a small part of them believe that standard financial institutions are the same with rural private credits. It does not matter for them. But it reflects that standard financial institutions have few differences from rural private credit. Standard financial institutions still leave much more to desire and to improve.

\section{Suggestions}

\subsection{Strength subsidies in the course of restoration and expansion of buildings and improve social welfare systems in rural areas.}

The existing social welfare system in our country provides a low level of benefit and not all-inclusive beneficial contents. In particular, there is little guarantee for living needs of restoration and expansion of buildings, which cannot meet the farmers needs of consumption. According to results of the investigation, rural private credit is significant for restoration and expansion of buildings and it reflects that social welfare mechanism in rural areas do not provide an all-round guarantee. As a result, the improvement of social welfare mechanism in rural areas is important for improving the living quality of farmers, standardizing rural financial markets and promoting a sound operation of rural private credit.

\subsection{Deepen financial reforms and protect legal rural private credit in accordance with the law.}

Rural private credit serves as an important part of the national financial sectors. Owing to the simplicity as well as convenience, rural private credit, to some extent, compensates for the shortcomings of standard financial institutions, satisfies farmers' needs for restoration and expansion of buildings, and improves farmers' living conditions, which mobilizes farmers' enthusiasm for productivity. Therefore, China shall encourage legal rural folk financial activities. China shall acknowledge the validity for those legal rural folk financial transactions that can improve farmers' living quality. Those financial transactions shall be included in the financial supervisory system and protected by the laws.

\subsection{Vigorous efforts shall be made for publicity and enhance farmers’'legal concept.}

Although farmers have an increasing awareness of laws in the course of debit and credit, relevant departments shall also strengthen farmers' legal awareness. Legal knowledge shall be popularized through risks prevention, contract improvement and law abidance to avoid unnecessary disputes in 
the course of debit and credit.

\section{Acknowledgment}

Construction of Teaching Case Database from the Perspective of Economic Management (Tibet Agriculture and Animal Husbandry University, the Central Award Supplementary Fund Project, 2018)

\section{References}

[1] Guo Zhenhai. Research on Financial Reform in Tibetan Agricultural and Pastoral Areas Based on Demand and Supply [J]. Financial Development Review, 2015(3).

[2] Kong Fanrong. Research on Influence of Private Lending on Household Consumption on the Condition of Critical Illness [J]. Seeker, 2013(9).

[3] Liu Jianjin. Rural Private Lending in China [J]. Chinese Rural Economy. 1993(3). 